macerate. The acid was prepared from Robison ester by bromoxidation, after Robison and King ${ }^{2}$. Part of the experiments was done with an almost pure preparation, which was most kindly supplied to me by Prof. R. Robison.

Bromoacetate, in a concentration which would entirely inhibit alcoholic fermentation $(0.01 \mathrm{~mol}$.), inactivates only partly. The oxygen consumption is almost unaffected, but carbon dioxide formation is reduced. In this case, per oxygen atom consumed nearly one mol. of carbon dioxide appeared. This might indicate that a primary oxidation and decarboxylation, unaffected by bromoacetate, is followed by a reaction, which may be of fermentative nature. This explanation seems to be corroborated by the experiments of Bernhauer and Görlich ${ }^{3}$ on the oxidation of gluconic acid effected by bacteria. They found $\alpha$-ketogluconic acid as one of the oxidation products. If now in yeast extract phosphogluconic acid is oxidized primarily to phospho- $\alpha$-ketogluconic acid by one atom of oxygen, this compound, being an $\alpha$-ketoacid, would easily split off carbon dioxide, giving rise to arabinosephosphate. The quotient $\mathrm{O}: \mathrm{CO}_{2}=1$, found in the presence of bromoacetate, would thus find its explanation.

Fluoride inhibits both oxygen absorption and carbon dioxide formation somewhat more strongly than bromoacetate.

During the oxidative fermentation of phosphogluconic acid, none or only a small amount of the phosphate is split off.

FrITz LIPMAN
Biological Institute of the Carlsberg Foundation, Copenhagen.

\footnotetext{
${ }^{1}$ Warburg, Christian und Griese, Biochem. Z., 882, 157 (1935)

'Robison and King, Biochem. J., 25, 323 (1931)
}

${ }^{3}$ Bernhauer und Görlich, Biochem. Z., 280, 367 (1935).

\section{A New Strigeid Parasite of the Rare Genus Cyathocotyle}

Is the course of my studies on the avian trema. todes of India, a preliminary report on which, dealing with Strigeidæ and Echinostomidæ, has already appeared ${ }^{1}$, one complete and one incomplete specimen of a new trematode were found which could not be included in the report above referred to. As the form is very interesting, a brief account of it is furnished here.

\section{Cyathocotyle calvusi n.sp.}

Body bulb-shaped, anteriorly swollen, posteriorly narrower; total length 2.06 (all measurements in millimetres on mounted specimens), maximum breadth $1 \cdot 02$, breadth of narrower region 0.038 . Oral sucker $0.15 \times 0.19$, ovoidal or circular, subterminal ; pharynx $0.09 \times 0.097$, nearly globular; cæca simple to near posterior end, broadly arched in front; cesophagus and prepharynx absent. Holdfast organ $0.32-0.4$ in diameter, centrally located in globular part, outline irregular, overlapped by vitelline follicles along outer margin; wall covered with very peculiar characteristic, hair-like, fibrous outgrowths. Testes very conspicuous, much elongated; anterior $0.56 \times 0.18$, alongside holdfast organ ; posterior $0.65 \times 0.18$, in narrower part of body, separated from the hind end by about half its length. Ovary roundish, 0.28 in diameter, masked by vitelline follicles, antero-lateral to hind testis. Vitellaria grouped in large follicles of irregular shape, along intestinal cæca meeting in front. Cirus sac $0.60 \times 0 \cdot 14$, about one-third as long as body, posteriorly drawn out into a long neck; contains coiled seminal vesicle, surrounded by prostatic cells in anterior half, and a long tubular, eversible cirrus in its posterior half. Genital atrium short, with male and female ducts opening side by side into it ; genital pore postero-terminal. Eggs about twice as long as thick, not many, 0.081$0.092 \times 0.042-0.047$. In intestine of King vulture, Torgos calvus (Scopoli), United Provinces.

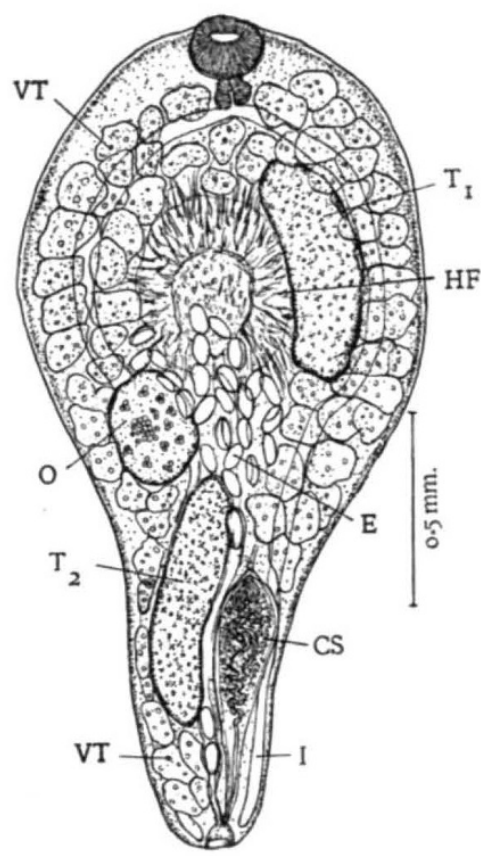

FIA. 1. Cyathocotyle calvusi n.sp. View of entire specimen.

Of the known species of the genus, the above worm is the largest, and stands somewhat close to C. orientalis Faust, 1921. But in addition to its larger size, it differs from it as well as from C. prussica Muehling, and $C$. melanittce Yamaguti, in its body shape, in its much longer and differently placed testes, in the differing proportion of its cirrus to body length and in size and position of ovary and size of eggs. It would appear to be new to science.

University, Allahabad.

S. C. VERMA.

Aug. 8

${ }^{1}$ Allahabad Univ. Stud., 12, 147-188 (1936).

\section{Occurrence of Haploid Pollen Mother Cells in a vulgare Wheat}

HAPLOID plants have been found in many species, but, so far as I am aware, there has been no recorded instance of haploid pollen mother cells occurring in a diploid plant. Bridges ${ }^{1}$ has found patches of haploid tissue in Drosophila.

During an examination of smear preparations of the meiotic chromosomes in a seventh generation $H 44 \times$ Reward wheat plant ( $H 44$ is a vulgare selection from the cross Yaroslav Emmer $\times$ Marquis), two 'haploid' pollen mother cells were found. One cell contained seven ring bivalents and seven univalents ; 